\title{
Tribute to the EAHP presidency of Roberto Frontini
}

\author{
Joan Peppard
}

Roberto Frontini, President of the European Association of Hospital Pharmacists (EAHP) from 2009 to 2015, contributed significantly to the development, recognition and evolution of the profession of hospital pharmacy in Europe and internationally.

Roberto Frontini studied pharmacy in the University of Hamburg, Germany, graduating in 1992 . He continued his studies, graduating in 1993 with his doctorate in pharmaceutical technology at which time he was employed by the University Hospital of Leipzig. He graduated with a specialisation degree in hospital pharmacy in 1996 when he took up the role as head of pharmacy at $\mathrm{St}$ Franziskus-Hospital, Cologne; he returned as director of pharmacy to the University Hospital of Leipzig in 2001.

\section{EAHP INVOLVEMENT}

In 2005 he was elected to the board of EAHP and immediately took up the position of financial director, a position he held until 2009. He was central to the strengthening of EAHP's financial position by re-negotiation and eventual insourcing of EAHP's annual congress. The long held EAHP goal of opening an office in Brussels was facilitated by his financial management as was the strategic hiring of an executive director in 2006, the first staff to be employed by EAHP. Roberto was voted president-elect in June 2008, and during that year introduced new branding for EAHP to better represent the organisation. The new logo was designed to reflect the three themes of pharmacy, Europe and hospital.

\section{ROBERTO AS PRESIDENT}

Roberto stepped up as EAHP president in June 2009. In 2011, Roberto set out his strategic plan for EAHP at the general assembly in Dublin- “to develop EAHP as an organisation that improves patient outcomes by engaging with all the

Correspondence to J Peppard, President, European Association of Hospital Pharmacists, Brussels, Belgium; joan.peppard@hse.ie stakeholders necessary to have an impact on healthcare".

A new position of policy and advocacy officer was established to enable a greater responsiveness by EAHP to influence policymakers at the European level to enhance patient care and also to enable the board members to focus on strategy and partnerships.

Roberto has advocated for patient care and the role of hospital pharmacists in a remarkable array of educational events, meetings and workshops where he expanded the knowledge not just to our pharmacy colleagues but to healthcare officials and university colleagues about the full potential of hospital pharmacists' contribution to optimising patient care, at the national, European and international levels.

Roberto's commitment to students epitomises his long term vision of hospital pharmacy. His passion for patient care drives him to inspire and motivate what he says is "the future of the profession". Roberto developed a student internship in the EAHP office.

\section{EUROPEAN STATEMENTS OF HOSPITAL PHARMACY}

His partnership approach to patient care was further demonstrated with the development of the European Statements of Hospital Pharmacy. Taking the 2008 FIP Basel Statements of Hospital Pharmacy as a baseline, Roberto Frontini took the unusual and courageous step of asking other healthcare professionals and patients to join with hospital pharmacists in setting out the role for hospital pharmacists in Europe. At a summit in May 2014, patient, healthcare professionals and hospital pharmacists voted on and agreed 44 statements in 6 practice areas that describe the hospital pharmacy practice that will ensure safe, effective and optimal use of medicines, with pharmacists working as part of and in collaboration with multidisciplinary teams.

The opportunity to achieve another of EAHP's long held goals was also achieved during the last year of Roberto's presidency. The amended professional qualifications directive means that a professional association such as EAHP can and is taking the lead in seeking recognition for free movement of hospital pharmacy specialists across Europe.

\section{LEADERSHIP STYLE}

Roberto recognises diversity in European hospital pharmacy with its different cultures, languages and points of view as a strength and an opportunity for learning and sharing of best practice across Europe. His style was one of inclusion, transparency, integrity and partnership. He held himself and all board members to high standards, introducing a code of conduct for board members and embracing transparency requirements. Under his leadership all decisions were taken with the long term aspiration of improving outcomes for patients through the knowledge and skills of hospital pharmacists and on the basis of a simple question-'is this the right thing to do'?

\section{COMMITMENT}

Roberto's enthusiasm and commitment to patient care remains undiminished by his Trojan effort as leader of the only representative organisation for hospital pharmacists in Europe.

He continues to advocate for patient safety and has, in his own hospital, established a patient safety centre in the last year. Roberto has been recognised by the American Society of Health System Pharmacists with the ASHP Donald E Francke Medal that honours pharmacists who have made significant international contributions to health system pharmacy.

As he leaves the board of EAHP to continue on his professional journey, I wish him well and extend to him deep appreciation for all he has contributed to the development, recognition and evolution of the profession of hospital pharmacy in Europe and internationally.

\section{Competing interests None declared.}

Provenance and peer review Commissioned: internally peer reviewed.

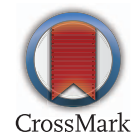

To cite Peppard J. Eur J Hosp Pharm 2016;23:64.

Published Online First 19 January 2016

Eur J Hosp Pharm 2016:23:64.

doi:10.1136/ejhpharm-2015-000865 